\title{
Control of Surface and Edge Oxidation on Phosphorene
}

\author{
Kaci L. Kuntz, ${ }^{\dagger}$ Rebekah A. Wells, ${ }^{\dagger}$ Jun Hu, ${ }^{\dagger}$ Teng Yang, ${ }^{\ddagger}$ Baojuan Dong, ${ }^{\ddagger}$ Huaihong Guo, ${ }^{\S}$ \\ Adam H. Woomer, ${ }^{\dagger}$ Daniel L. Druffel, ${ }^{\dagger}$ Anginelle Alabanza, ${ }^{\dagger}$ David Tománek,, \\ and Scott C. Warren ${ }^{*}, \dagger, \perp \odot$
}

${ }^{\dagger}$ Department of Chemistry, University of North Carolina at Chapel Hill, Chapel Hill, North Carolina 27599, United States

${ }^{\ddagger}$ Shenyang National Laboratory for Materials Science, Institute of Metal Research, Chinese Academy of Sciences, Shenyang 110016, P.R. China

${ }^{\S}$ College of Sciences, Liaoning Shihua University, Fushun 113001, P.R. China

"Physics and Astronomy Department, Michigan State University, East Lansing, Michigan 48824, United States

${ }^{\perp}$ Department of Applied Physical Sciences, University of North Carolina at Chapel Hill, Chapel Hill, North Carolina 27599, United States

\section{Supporting Information}

ABSTRACT: Phosphorene is emerging as an important twodimensional semiconductor, but controlling the surface chemistry of phosphorene remains a significant challenge. Here, we show that controlled oxidation of phosphorene determines the composition and spatial distribution of the resulting oxide. We used X-ray photoemission spectroscopy to measure the binding energy shifts that accompany oxidation. We interpreted these spectra by calculating the binding energy shift for 24 likely bonding configurations, including phosphorus oxides and hydroxides located on the basal surface or edges of flakes. After brief exposure to high-purity oxygen or high-purity water vapor at room temperature, we observed phosphorus in the +1 and +2 oxidation states; longer

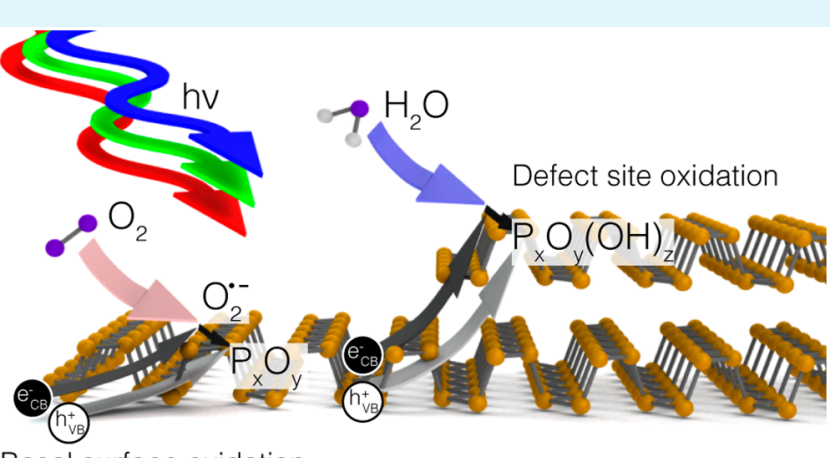

Basal surface oxidation exposures led to a large population of phosphorus in the +3 oxidation state. To provide insight into the spatial distribution of the oxide, transmission electron microscopy was performed at several stages during the oxidation. We found crucial differences between oxygen and water oxidants: while pure oxygen produced an oxide layer on the van der Waals surface, water oxidized the material at pre-existing defects such as edges or steps. We propose a mechanism based on the thermodynamics of electron transfer to interpret these observations. This work opens a route to functionalize the basal surface or edges of two-dimensional (2D) black phosphorus through site-selective chemical reactions and presents the opportunity to explore the synthesis of $2 \mathrm{D}$ phosphorene oxide by oxidation.

KEYWORDS: 2D materials, black phosphorus, phosphorene, oxidation, surface functionalization, edge functionalization, DFT, binding energy shift

\section{INTRODUCTION}

In two-dimensional (2D) materials, the majority of atoms are located at surfaces; therefore, surface chemistry is important in determining intrinsic properties. For example, graphene is a zero gap $2 \mathrm{D}$ semimetal with ultrahigh mobility and conductivity, ${ }^{1,2}$ while graphene oxide can be insulating or semiconducting. $^{2-5}$ In emerging materials such as phosphorene-the $2 \mathrm{D}$ form of black phosphorus-understanding and controlling surface chemistry is considered essential to future applications of the material. $^{6-9}$

Like graphene and graphene oxide, phosphorene and phosphorene oxide have exceptional properties. Phosphorene is especially interesting because it has a thickness-dependent band gap that ranges from $0.3 \mathrm{eV}$ in bulk to approximately 2.1 $\mathrm{eV}$ in a monolayer, ${ }^{10-15}$ a range that is greater than most quantum dots. Furthermore, 2D black phosphorus has optical and electrical anisotropy, ${ }^{16-18}$ high carrier mobility, ${ }^{13,19,20}$ and both $\mathrm{n}$ - and p-type behavior. ${ }^{13,21,22}$ These properties suggest potential uses in optoelectronic technologies, including transistors, ${ }^{20,21,23}$ solar energy conversion, ${ }^{22,24-26}$ and photodetectors. ${ }^{18,27,28}$ Many other types of applications, including batteries, ${ }^{29,30}$ gas sensors, ${ }^{31-34}$ catalysts, $^{26,35}$ and medicine, ${ }^{35,36}$ require control over phosphorene's surface chemistry and reactivity.

Phosphorene and black phosphorus are known to oxidize in ambient conditions, ${ }^{6,7,37-42}$ yielding insulating phosphorene

Received: December 15, 2016

Accepted: February 20, 2017

Published: February 20, 2017 

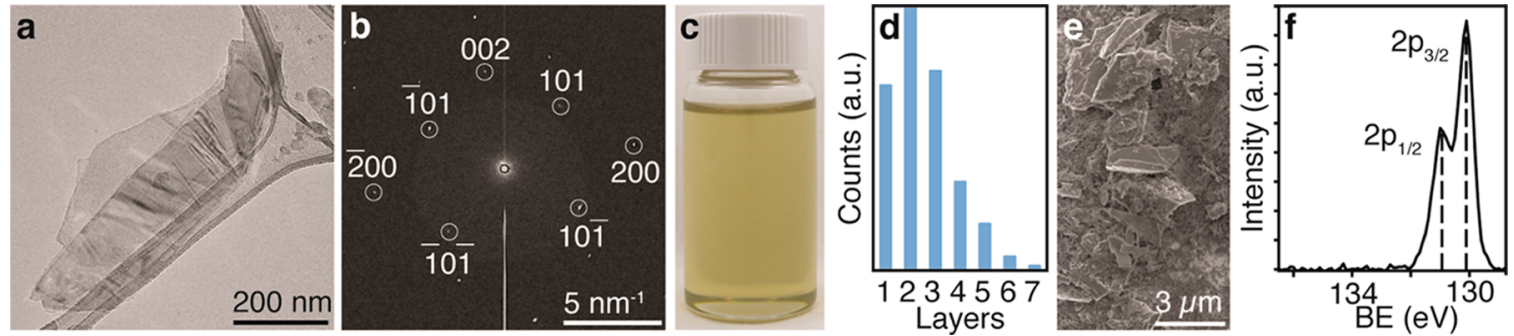

Figure 1. Liquid exfoliation of black phosphorus and characterization of thin films. (a) TEM image of an unoxidized 2D black phosphorus flake. (b) The diffraction pattern of the thinner region is consistent with a monolayer of phosphorene. (c) A centrifuged solution of $2 \mathrm{D}$ black phosphorus suspended in NMP. (d) The thickness distribution of the 2D suspension ranges from 1 to 7 layers. (e) SEM image showing the topology of a doctor bladed thin film of $2 \mathrm{D}$ black phosphorus. (f) XPS spectrum of the phosphorus $2 \mathrm{p}$ core electrons of an unoxidized $2 \mathrm{D}$ black phosphorus film: the photoemission peaks, $2 \mathrm{p}_{3 / 2}$ and $2 \mathrm{p}_{1 / 2}$, are centered at 130.1 and $131.0 \mathrm{eV}$, respectively.

oxides and low atomic weight fragments. ${ }^{43}$ These oxides have tunable properties that depend on composition; for example, band gaps up to $8.5 \mathrm{eV}$ have been predicted, ${ }^{33,39}$ and photoluminescence has been observed. ${ }^{44}$ With a tunable band gap from semiconducting to insulating and interesting electronic properties, ${ }^{33,39,45} 2 \mathrm{D}$ phosphorene oxide demonstrates potential use in optoelectronics such as an electronic on/off switch, ${ }^{33,39,45}$ a transparent encapsulation layer, ${ }^{33,39,45}$ or a gas sensor. ${ }^{33}$ The observation that phosphorene oxidizes under ambient conditions suggests that oxidation reactions are an important class of surface reaction chemistries that could be used to functionalize phosphorene's surface. The development of oxidation chemistries may also provide new pathways to stabilize phosphorene against degradation under ambient conditions.

This work investigates the oxides of $2 \mathrm{D}$ black phosphorus through experimental surface characterization coupled with simulations to explore how oxidant conditions modify the surface chemistry of $2 \mathrm{D}$ phosphorene oxide at defect (edge, step, grain boundary, etc.) and nondefect sites. We present evidence for the selective oxidation of the van der Waals surface (i.e., the basal surface) or edges and other defect sites of fewlayer phosphorene through the choice of oxidant. Ultimately, the ability to selectively modify the basal surface or edge states presents opportunities to engineer the properties of $2 \mathrm{D}$ materials through covalent functionalization and defect passivation.

Many techniques have been used to study the oxidation of black phosphorus, providing insights into the chemical composition, electronic structure, and physical properties of the material. It is well-documented that black phosphorus oxidizes in ambient conditions, forming various phosphorus oxides, $\mathrm{P}_{x} \mathrm{O}_{y}(\mathrm{OH})_{z}{ }^{37,46}$ These oxidized species include single $(\mathrm{P}-\mathrm{O})$ and double $(\mathrm{P}=\mathrm{O})$ bonds, ${ }^{38}$ which may be dangling $(\mathrm{P}-\mathrm{OH}, \mathrm{P}=\mathrm{O})$ or bridging $(\mathrm{P}-\mathrm{O}-\mathrm{P}) .{ }^{6,33,47}$ While more needs to be understood about the surface reactivity of black phosphorus, two possible outcomes include the development of a self-limited phosphorene oxide that protects and passivates phosphorene as well as the synthesis of a stable monolayer of phosphorene oxide, ${ }^{6,33,38,40,48,49}$ the analogue of graphene oxide.

Water, oxygen, and light are known to play important roles in the rate, composition, and mechanism of black phosphorus oxidation, ${ }^{37,38,40-42,50}$ but the contribution of each factor is actively debated with many studies in strong disagreement. Nearly all experiments are performed under ambient conditions, so the effects of single oxidants, $\mathrm{O}_{2}$ or $\mathrm{H}_{2} \mathrm{O}$, are not well understood. Samples exposed to $\mathrm{O}_{2}$ and $\mathrm{H}_{2} \mathrm{O}$ simultaneously demonstrated a decrease in the ratio of the $\mathrm{A}_{\mathrm{g}}{ }^{1}: \mathrm{A}_{\mathrm{g}}{ }^{2}$ Raman active modes, ${ }^{37}$ degradation in transmission electron microscopy (TEM) images, ${ }^{38}$ and the presence of phosphorus oxides on the surface of the material in X-ray photoelectron spectroscopy (XPS). ${ }^{35,38,42,51}$ In contrast, for single component $\left(\mathrm{H}_{2} \mathrm{O}\right.$ or $\mathrm{O}_{2}$ or light) exposures, TEM and Raman spectroscopy indicated that the material did not oxidize. $^{35,37,51}$ However, more surface sensitive techniques such as XPS show that phosphorus oxides are present with single-oxidant exposures. ${ }^{35,42,51}$ Recent work deconvoluted experimental XPS spectra by simulating the binding energy shifts of a limited number of phosphorus oxides and demonstrated that oxides of $2 \mathrm{D}$ black phosphorus exposed to ambient air or high-purity $\mathrm{O}_{2}$ are compositionally different. ${ }^{47}$ Despite the advances in characterizing the composition of the oxide, the earlier study neglected low oxidation states of phosphorus and did not examine the composition of the oxide produced by only $\mathrm{H}_{2} \mathrm{O}$ exposure. Herein, we characterize the oxide after exposure to high-purity $\mathrm{O}_{2}, \mathrm{H}_{2} \mathrm{O}$, or both oxidants and interpret the resulting XPS spectra by simulating the binding energy shift for several oxides that have not been previously considered, including those that have low oxidation states and that may form at edges of $2 \mathrm{D}$ flakes.

In addition to understanding the oxide composition, the mechanism of oxidation of black phosphorus has been explored. Proposed mechanisms involve a multistep reaction: initially photoexcited black phosphorus transfers one electron to $\mathrm{O}_{2}$, creating superoxide, ${ }^{37,46,50}$ a strong oxidant that then reacts with phosphorene to produce phosphorus oxides. Some of these oxides, such as phosphorus pentoxide, $\mathrm{P}_{2} \mathrm{O}_{5},{ }^{46,49}$ are strong desiccants that readily react with water to produce phosphoric acid or other acids. This model is supported by the observation of a decrease in $\mathrm{pH}$ during oxidation. ${ }^{10}$ An additional mechanism to $\mathrm{O}_{2}$-initiated oxidation is one in which $\mathrm{H}_{2} \mathrm{O}$ may initiate the oxidation of black phosphorus. Black phosphorus exposed to deoxygenated $\mathrm{H}_{2} \mathrm{O}$ exhibited the presence of phosphorus oxides in XPS measurements, ${ }^{35,42,51}$ providing strong evidence that oxidation can be initiated by $\mathrm{H}_{2} \mathrm{O}$. With evidence for oxidation by $\mathrm{H}_{2} \mathrm{O}$ or $\mathrm{O}_{2}$, this work characterizes the oxidized material after exposure to $\mathrm{O}_{2}, \mathrm{H}_{2} \mathrm{O}$, or $\mathrm{H}_{2} \mathrm{O}$ and $\mathrm{O}_{2}$ to understand the variations that result from different oxidant exposures. We explore the potential to oxidize defect (e.g., edge states) or nondefect (e.g., basal surface) sites of $2 \mathrm{D}$ black phosphorus by the different mechanisms of oxidation by $\mathrm{H}_{2} \mathrm{O}$ and $\mathrm{O}_{2}$.

As with graphene and graphene oxide, the potential to control the composition of the oxide of black phosphorus is a step toward chemical functionalization. Employing this tunable 


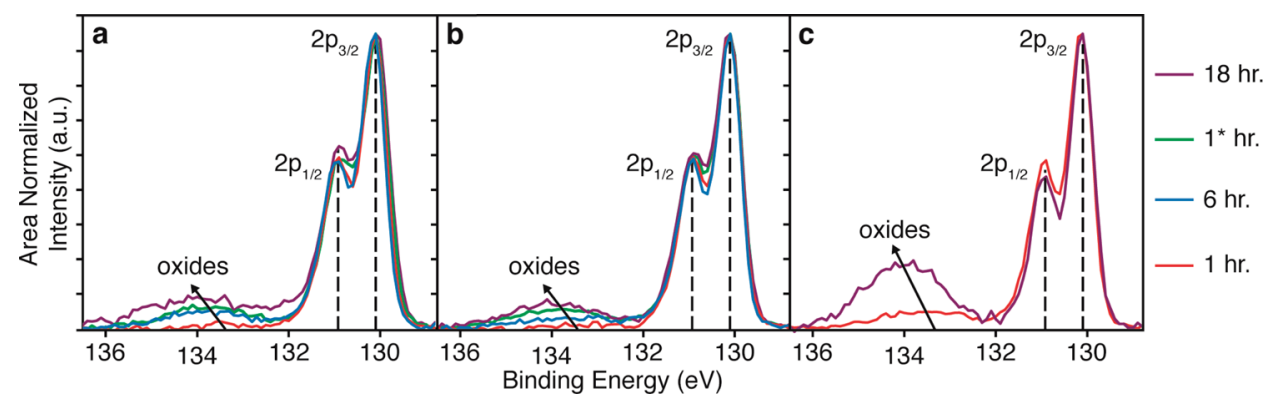

Figure 2. XPS spectra of 2D black phosphorus films exposed to various oxidants in the gas phase: (a) $\mathrm{O}_{2}(99.999 \%),\left(\right.$ b) $\mathrm{H}_{2} \mathrm{O} / \mathrm{N}_{2}(99.998 \%)$, and (c) $\mathrm{H}_{2} \mathrm{O} / \mathrm{O}_{2}$. As the time of exposure increased, the quantity of phosphorus oxides increased, as shown by the arrows. The red/blue/purple lines indicate $1 / 6 / 18 \mathrm{~h}$ of oxidant exposure, respectively. The green line, $1^{*}$, represents series-exposed oxidation in which a sample was exposed to a single oxidant for $5 \mathrm{~min}$, evacuated, and then exposed to the other oxidant for $1 \mathrm{~h}$ : (a) $\mathrm{H}_{2} \mathrm{O} / \mathrm{N}_{2}$, then $\mathrm{O}_{2}$ and (b) $\mathrm{O}_{2}$, then $\mathrm{H}_{2} \mathrm{O} / \mathrm{N}_{2}$. The 6 h exposures for $\mathrm{H}_{2} \mathrm{O} / \mathrm{O}_{2}$ oxidants were contaminated and are therefore not shown.

$2 \mathrm{D}$ material and its oxide requires: (1) exposing the material to high-purity oxidants, (2) spatially resolving the location and composition of the oxide, and (3) elucidating the mechanism of oxidation, ultimately providing control of the oxide formation by choice of oxidant. This work characterizes $2 \mathrm{D}$ black phosphorus thin films and individual flakes through photoemission spectroscopy and TEM after exposure to (i) $\mathrm{O}_{2}$, (ii) $\mathrm{H}_{2} \mathrm{O}$, (iii) mixtures of $\mathrm{H}_{2} \mathrm{O}$ and $\mathrm{O}_{2}$, and (iv) $\mathrm{N}_{2}$ environments. We demonstrate an improved understanding of the resulting oxide composition through deconvolution of XPS spectra and visualization of the oxide location through time-lapsed TEM images. In addition, we find evidence for site-selective oxidation of 2D black phosphorus at defect (e.g., edge states) or nondefect (e.g., basal surface) sites by choice of oxidant and provide a possible mechanism for the oxidation of phosphorene by $\mathrm{H}_{2} \mathrm{O}$.

\section{EXPERIMENTAL SECTION}

2.1. Material Preparation. Bulk black phosphorus crystals were synthesized by a $\mathrm{Sn}$ and $\mathrm{SnI}_{4}$ vapor transport method. ${ }^{10,52}$ Under an inert atmosphere $\left(\mathrm{O}_{2}<1 \mathrm{ppm}, \mathrm{H}_{2} \mathrm{O}<0.1 \mathrm{ppm}\right)$, we then prepared $2 \mathrm{D}$ black phosphorus (Figures 1a and b) by liquid exfoliation of bulk crystals in anhydrous $\mathrm{N}$-methyl-2-pyrrolidone (NMP). Centrifugation of the resulting suspension yielded flakes ranging from 1 to 7 layers with a median of bilayers (Figures $1 \mathrm{c}$ and $\mathrm{d}$ ). ${ }^{10}$ The diffraction pattern (Figure 1b) of the thinnest region of the flake (Figure 1a) is consistent with a monolayer of black phosphorus. ${ }^{54}$ Under an inert atmosphere, we redispersed the $2 \mathrm{D}$ material in isopropanol and deposited flakes onto lacey carbon TEM grids by drop casting (Figure 1a). We prepared thin films of 2D black phosphorus on hydrophilic gold-plated silicon wafers using the doctor blade technique under an inert atmosphere (Figure S1). ${ }^{53}$ A scanning electron microscope (SEM) image of the topology of the $2 \mathrm{D}$ black phosphorus film is shown in Figure 1e.

2.2. Oxidant Exposure. The $2 \mathrm{D}$ black phosphorus thin film assemblies and individual flakes were exposed (Figure S1) to (i) $\mathrm{O}_{2}$, (ii) $\mathrm{H}_{2} \mathrm{O} / \mathrm{N}_{2}$, (iii) mixtures of $\mathrm{H}_{2} \mathrm{O} / \mathrm{O}_{2}$, or (iv) maintained under inert atmosphere, $\mathrm{N}_{2}$. Research grade (i) $\mathrm{O}_{2}$ ( $99.999 \%$ purity) flowed over a $\mathrm{P}_{2} \mathrm{O}_{5}$ desiccant prior to reaching the phosphorus sample, ensuring an environment devoid of $\mathrm{H}_{2} \mathrm{O}$. To create (ii) $\mathrm{H}_{2} \mathrm{O} / \mathrm{N}_{2}$ or (iii) $\mathrm{H}_{2} \mathrm{O} / \mathrm{O}_{2}$ oxidants, distilled $\mathrm{H}_{2} \mathrm{O}$ was heated to $100{ }^{\circ} \mathrm{C}$ and purged with (ii) $\mathrm{N}_{2}$ (99.998\%) or (iii) $\mathrm{O}_{2}$ for at least $30 \mathrm{~min}$; carrier gases of (ii) $\mathrm{N}_{2}$ or (iii) $\mathrm{O}_{2}$ were used to flow water vapor over the sample. The thin films (containing $<0.01$ micromoles of $\mathrm{P}$ ) and individual flakes on TEM grids were exposed to oxidant gas flow for $5 \mathrm{~min}$ and sealed with 5 mmol of oxidant species, a significant excess of oxidant compared to the phosphorus. In each of these exposures, the oxidants equilibrated to room temperature upon reaching the sample. Then, each sample was illuminated by a $460 \mathrm{~nm}$ LED with an intensity of $0.6 \mathrm{~mW} / \mathrm{cm}^{2}$ at room temperature $\left(\sim 25^{\circ} \mathrm{C}\right)$. After 1,6 , or $18 \mathrm{~h}$, the sample was removed from illumination, placed under vacuum, and stored under an inert atmosphere.

2.3. Characterization. Samples were maintained under an inert atmosphere during transport and loading procedures, unless otherwise stated. Resulting oxides of the thin films were characterized by XPS using a Kratos Axis Ultra Delay-Line Detector (DLD) spectrometer with monochromatic $\mathrm{Al} \mathrm{K} \alpha$ source. Individual flakes were imaged using a low-resolution JEOL 100CX II TEM at an accelerating voltage of $80 \mathrm{kV}$. Thin films were imaged using a Hitachi S-4700 cold cathode field emission SEM at an accelerating voltage of $2 \mathrm{kV}$.

\section{RESULTS AND DISCUSSION}

3.1. XPS Characterization. We used XPS to investigate the core electron binding energies of phosphorus $2 p$ electrons. Unoxidized 2D black phosphorus films (Figure 1f) exhibit $2 \mathrm{p}_{3 / 2}$ and $2 \mathrm{p}_{1 / 2}$ peaks at 130.1 and $131.0 \mathrm{eV}$, respectively; these values are in good agreement with known bulk black phosphorus $2 \mathrm{p}$ peak positions. ${ }^{6,55-57}$ Additionally, 2D black phosphorus thin films exposed to a single oxidant, $\mathrm{O}_{2}$ (Figure 2a) or $\mathrm{H}_{2} \mathrm{O} / \mathrm{N}_{2}$ (Figure 2b), or two oxidants, $\mathrm{H}_{2} \mathrm{O} / \mathrm{O}_{2}$ (Figure $2 \mathrm{c})$, have the same $2 \mathrm{p}$ doublet peaks at 130.1 and $131.0 \mathrm{eV}$, confirming that most phosphorus remains unoxidized.

The presence of electronegative groups such as oxygen or hydroxide on the surface withdraw charge from black phosphorus, leading to more tightly bound phosphorus electrons. As a result, phosphorus oxide species experience phosphorus $2 \mathrm{p}$ core electron binding energies, $E_{\mathrm{B}}{ }^{\mathrm{F}}$, higher than that of unoxidized material. Our previous calculations showed that $2 \mathrm{D}$ black phosphorus oxides with phosphorus oxidation states of $+2,+3$, or +5 have binding energies in the range of $132-136 \mathrm{eV} .^{47}$ The photoemitted $2 \mathrm{p}$ core electrons of oxidized 2D black phosphorus films (Figure 2) have a broad phosphorus oxide peak from 132 to $136 \mathrm{eV}$. As exposure time of the 2D film increased, the relative quantity of phosphorus oxides increased, indicated by the growth of the oxide peak relative to the black phosphorus doublet (Figure 2). Additionally, the peak maximum simultaneously shifted to higher binding energies, indicating a change in the composition of phosphorus oxides.

The oxidation of few-layer phosphorene by a single oxidant, $\mathrm{O}_{2}$ (Figure 2a) or $\mathrm{H}_{2} \mathrm{O} / \mathrm{N}_{2}$ (Figure 2b), is slower than oxidation by two oxidants, $\mathrm{H}_{2} \mathrm{O} / \mathrm{O}_{2}$ (Figure 2c). The accelerated rate of oxidation in the presence of two oxidants may indicate a multistep or catalyzed mechanism. To explore these possibilities, we exposed 2D black phosphorus films to a series of gases: (i) $\mathrm{H}_{2} \mathrm{O} / \mathrm{N}_{2}$, then $\mathrm{O}_{2}$ or (ii) $\mathrm{O}_{2}$, then $\mathrm{H}_{2} \mathrm{O} / \mathrm{N}_{2}$. Herein, we refer to these as series-exposed (i) $\mathrm{O}_{2}$ or (ii) $\mathrm{H}_{2} \mathrm{O}$ 

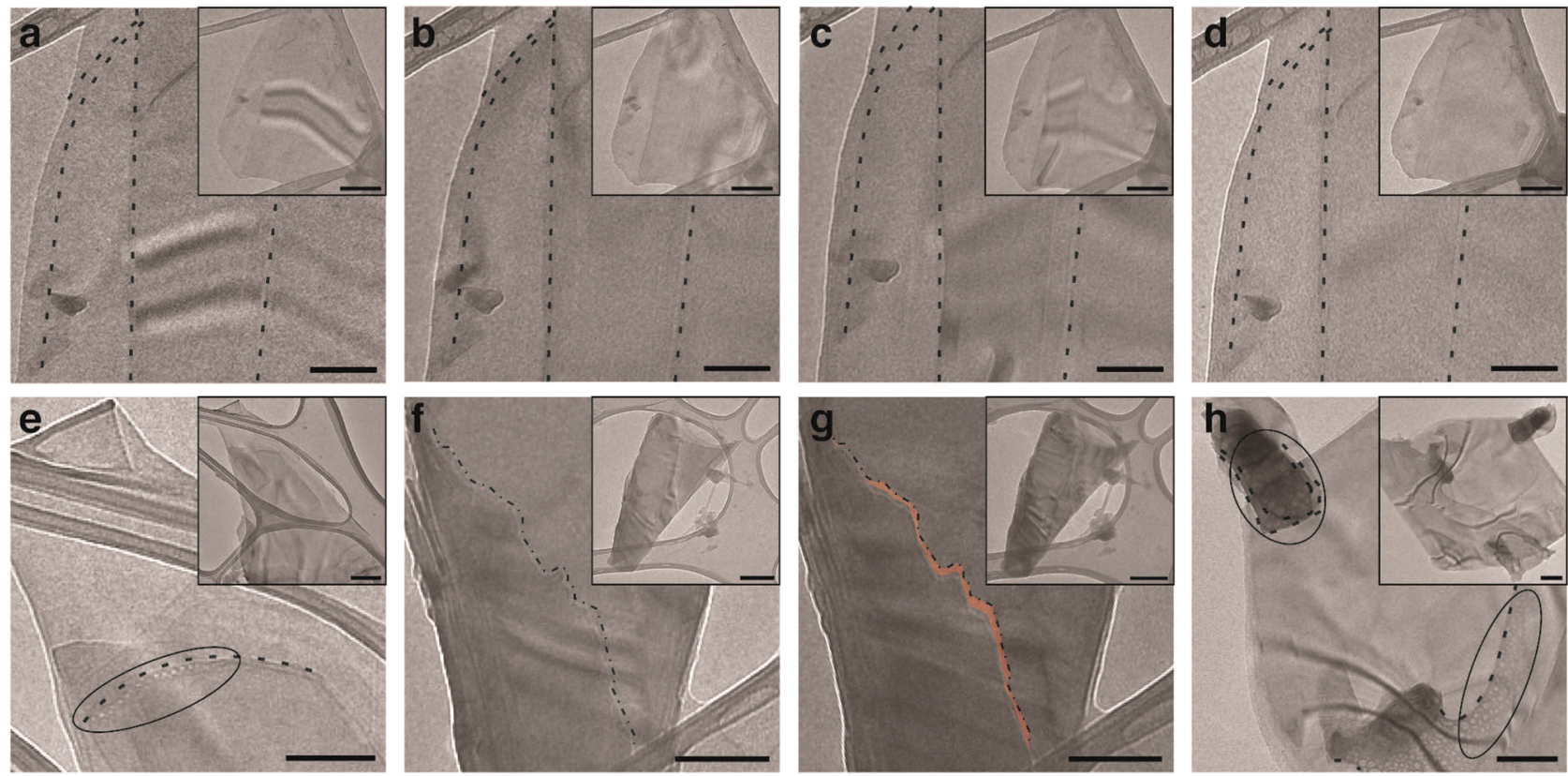

Figure 3. TEM images of $2 \mathrm{D}$ black phosphorus exposed to different oxidants. (a) An unoxidized 2D black phosphorus flake, where steps are indicated by dashed lines, was exposed to $\mathrm{O}_{2}$ (99.999\%) for (b) 1, (c) 6, and (d) 18 h. (e) A flake exposed to $\mathrm{H}_{2} \mathrm{O} / \mathrm{N}_{2}(99.998 \%$ ) demonstrated pitting at the thicker side of a step after $6 \mathrm{~h}$. (f) An unoxidized black phosphorus flake with the step indicated with a dash-dot line; (g) after exposure to $\mathrm{H}_{2} \mathrm{O} / \mathrm{N}_{2}(99.998 \%)$ for $18 \mathrm{~h}$, the step exhibited a loss of material, represented by the highlighted orange region adjacent to the original edge (dash-dot line). (h) After extended exposure to ambient conditions $(76 \mathrm{~h})$, pitting at the thicker side of steps occurred and extended farther into the thicker sides of the flake. Each scale bar is $100 \mathrm{~nm}$. Insets are a lower magnification of the flake shown in the respective image; each inset scale bar is $200 \mathrm{~nm}$.

samples, respectively. In each of these cases, the first exposure to a single oxidant lasted $5 \mathrm{~min}$ and was performed in dark conditions, evacuated for $45 \mathrm{~min}$, resealed under $\mathrm{N}_{2}$, and then exposed to the other oxidant and illuminated for $1 \mathrm{~h}$ (see the Supporting Information for more details). Each series-exposed sample formed more oxide than the respective single oxidant sample (Table S1). This suggests that trace quantities of residual $\mathrm{O}_{2}, \mathrm{H}_{2} \mathrm{O}$, or reaction byproducts accelerate or catalyze oxidation. Because the residual content of $\mathrm{H}_{2} \mathrm{O}$ or $\mathrm{O}_{2}$ was far less than the amount of oxidized material, we conclude that the reaction byproducts rather than the initial oxidants are primarily responsible for the increased rate of oxidation. This observation is consistent with a mechanism in which the oxide makes the material far more susceptible to oxidation, possibly by a catalytic process. This observation also highlights the difficulty of designing a self-passivating oxide on phosphorene.

3.2. Time-Lapsed TEM. To understand where oxidation was occurring, we conducted a time-lapsed TEM study of individual flakes to visualize physical modifications after exposure to $\mathrm{O}_{2}$ (99.999\%), $\mathrm{H}_{2} \mathrm{O} / \mathrm{N}_{2}$ (99.998\%), or ambient conditions. To verify that observed changes were not attributed solely to knock-on damage from the TEM, we imaged a new flake at each time interval in addition to imaging all previously viewed flakes. A representative unoxidized 2D black phosphorus flake is shown in Figure 3a. The same flake was then exposed to high-purity $\mathrm{O}_{2}(99.999 \%)$ for 1,6 , and 18 cumulative hours, shown in Figures $3 b-d$, respectively. Small changes in diffraction contrast are apparent in these images, which are a consequence of small changes in the tilt of the sample with respect to the electron beam. No other changes such as etching, bubble formation, or any other large changes in contrast in $\mathrm{O}_{2}$-exposed flakes were observed. The absence of these changes as the phosphorus oxide formed (Figure 2a) indicates that the oxide layer must be relatively uniform across the basal (i.e., van der Waals) surface of phosphorene because an inhomogeneous oxide would give rise to considerable mass contrast in our thin $2 \mathrm{D}$ phosphorus samples. Thus, we find that exposure to high purity oxygen produces a relatively uniform oxide on the van der Waals surface and could also lead to novel materials such as a $2 \mathrm{D}$ phosphorene oxide.

For flakes exposed to $\mathrm{H}_{2} \mathrm{O} / \mathrm{N}_{2}$ (99.998\%), pitting on the thicker side of steps was observed, as shown in Figure 3e. In Section 3.5, we examine the mechanism of this observed oxidation. As exposure to $\mathrm{H}_{2} \mathrm{O}$ continued, etching at edges and steps was also observed, demonstrated for a step in Figure $3 \mathrm{f}$ (unoxidized) and Figure $3 \mathrm{~g}\left(18 \mathrm{~h}\right.$ in $\left.\mathrm{H}_{2} \mathrm{O} / \mathrm{N}_{2}\right)$. These observations imply that photoexcited $2 \mathrm{D}$ black phosphorus can be oxidized by $\mathrm{H}_{2} \mathrm{O}$, validating previous experimental observations. $^{32,35,51}$ Our TEM images suggest a mechanism in which water preferentially oxidizes defect sites, especially those at edges and steps.

Samples exposed to ambient conditions (Figure $3 \mathrm{~h}$ ) showed the same pitting at steps as observed in $\mathrm{H}_{2} \mathrm{O} / \mathrm{N}_{2}$ environments. We found $94 \%$ of flakes exposed to ambient conditions demonstrated pitting for exposure times spanning $1-100 \mathrm{~h}$ with a confidence interval of $90-100 \%$ (Table 1). For longer exposure times, pit diameters increased in width, especially in

Table 1. Observed Oxidation Mechanisms in Ambient Conditions for $1-100 \mathrm{~h}$

$\begin{array}{lccc} & \text { mean }(\%) & \text { confidence interval (\%) } & \text { sample size } \\ \text { pitting at steps } & 94 & 90-100 & 77 \\ \text { loss of edges } & 62 & 54-68 & 37 \\ \text { surface pitting } & 75 & 65-78 & 58 \\ \text { loss of layer(s) } & 56 & 50-67 & 36\end{array}$


thicker regions of the material (see Figure $3 \mathrm{~h}$ ). We refer to this mechanism of oxidation as surface pitting, and it was observed in $75 \%$ of flakes imaged at consecutive time intervals. Furthermore, loss of material at edges was observed in $62 \%$ of flakes consecutively imaged after ambient exposure. For longer exposures, the combination of pitting at steps, loss of edges, and surface pitting can ultimately result in loss of an entire layer of a 2D flake. Table 1 summarizes these results.

Our experiments demonstrate that the mechanism of oxidation of $2 \mathrm{D}$ black phosphorus depends on the oxidant; high-purity $\mathrm{O}_{2}$ leads to an oxide layer on the basal surface of 2D phosphorus, while $\mathrm{H}_{2} \mathrm{O}$ causes physical degradation of the material through pitting on the thicker sides of steps and material loss at edges. Recently, s-SNOM was used to characterize the degradation mechanism of mechanically exfoliated bulk black phosphorus and $1 \mathrm{~nm} \mathrm{Al}_{2} \mathrm{O}_{3}$-encapsulated 2D black phosphorus in air; oxidation began at edges, steps, and surface defects, ${ }^{40}$ suggesting a similar mechanism of degradation for ambient-exposed liquid and mechanically exfoliated samples.

3.3. Binding Energy Shift, $\Delta E_{\mathrm{B}}{ }^{\mathrm{F}}$, of Phosphorus Oxides. The ability to characterize the basal surface and edge oxides resulting from high-purity $\mathrm{O}_{2}$ or $\mathrm{H}_{2} \mathrm{O}$ oxidation would provide information about the surface chemistry of $2 \mathrm{D}$ black phosphorus. Previous work simulated the XPS binding energy for basal surface and molecular oxides in the $+2,+3$, and +5 oxidation states. ${ }^{47}$ With our new evidence for oxidation at the edge of flakes and the possibility of forming phosphorus in a +1 oxidation state, more simulations are needed to comprehensively characterize the phosphorus oxides from XPS spectra.

A convenient way to calculate the core-level binding energy $\Delta E_{\mathrm{B}}{ }^{\mathrm{F}}$ between inequivalent sites in the sample involves a thermodynamic Born-Haber cycle, which subdivides the transition from the initial ground state to the fully screened final state of the solid system into steps involving either groundstate processes such as desorption or adsorption of specific atoms from the solid, or photoexcitation and de-excitation processes in isolated atoms (Figure 4). A core assumption is the "equivalent cores" or " $\mathrm{Z}+1$ " approximation, ${ }^{58}$ which considers (for the duration of the photoemission process) a phosphorus atom with a missing core electron to be equivalent to a sulfur atom with an extra proton $(\mathrm{Z}+1)$ in the nucleus and a missing valence electron. In the fully screened final state, the valenceionized sulfur atom turns neutral by acquiring an additional valence electron. Thus, the photoemission and screening segments of the Born-Haber cycle involve isolated atoms only and drop out in the difference of core-level binding energies (Figure 4b). The Born-Haber cycle is depicted in Figure $4 \mathrm{a}$, and details of the Born-Haber cycle as applied to oxidizing phosphorene are provided in ref 47.

The usefulness of this approach has been demonstrated previously. ${ }^{47,59-61}$ In the present case, calculation of a particular phosphorus core-level binding-energy shift $\Delta E_{\mathrm{B}}{ }^{\mathrm{F}}$ at a specific site involves the total-energy calculation of an unoxidized or oxidized phosphorene monolayer and of the corresponding system, where the phosphorus atom of interest has been substituted by a sulfur atom (Figure 4). ${ }^{47}$ Precise differences between these total energies can be obtained using ab initio density functional theory (DFT) calculations that consider valence electrons only.

The total energy calculations of structures, which are needed to determine specific core-level binding-energy shifts $\Delta E_{\mathrm{B}}{ }^{\mathrm{F}}$,

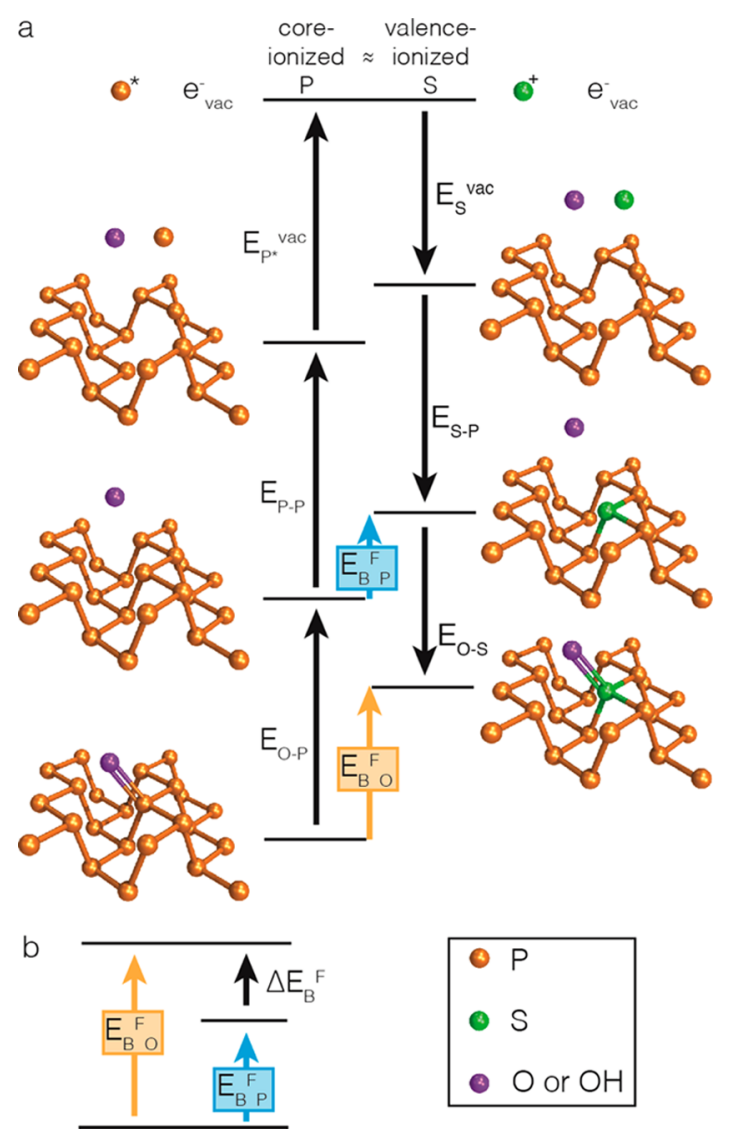

Figure 4. Depiction of the thermodynamic Born-Haber cycle for oxidized phosphorene. (a) The thermodynamic Born-Haber cycle allows the core-electron binding energy of unoxidized $\left(E_{\mathrm{B}}{ }_{\mathrm{p}}^{\mathrm{F}}\right)$ and oxidized $\left(E_{\mathrm{B}}^{\mathrm{F}} \mathrm{O}\right)$ phosphorene to be calculated. For unoxidized material, the energy of cohesion $\left(E_{\mathrm{P}-\mathrm{P}}\right)$ of the phosphorus atom is calculated. Then, a core-electron is photoexcited to the vacuum level $\left(E_{\mathrm{P} *}{ }^{\mathrm{vac}}\right)$. The core-ionized phosphorus atom $\left(\mathrm{P}^{*}\right)$ is approximated to be an equivalent valence-ionized sulfur atom $\left(\mathrm{S}^{+}\right)$. As the sulfur ion recombines, the energy released is the calculated ionization energy $\left(E_{\mathrm{S}}{ }^{\mathrm{vac}}\right)$. Finally, the sulfur is returned to the original phosphorus atom's site, releasing the energy of cohesion $\left(E_{S-\mathrm{P}}\right)$. The difference between the initial and final states is equivalent to the core-electron binding energy of a phosphorus atom in unoxidized phosphorene $\left(E_{\mathrm{B}}{ }_{\mathrm{p}}^{\mathrm{F}}\right)$. Two additional steps are added to the start and end of the cycle for an oxidized phosphorus atom: the energy required to desorb the oxide species from the phosphorus atom $\left(E_{\mathrm{O}-\mathrm{P}}\right)$ and the energy released when the oxide species adsorbs to the sulfur atom $\left(E_{\mathrm{O}-\mathrm{S}}\right)$. The difference between the initial and final states of this cycle is equivalent to the core-electron binding energy of a phosphorus atom in oxidized phosphorene $\left(E_{\mathrm{B}}{ }_{\mathrm{F}} \mathrm{O}\right)$. (b) The difference in energy between these two processes allows for the core-electron binding energy shift $\left(\Delta E_{\mathrm{B}}{ }^{\mathrm{F}}\right)$ to be calculated.

were performed using DFT with a plane-wave basis, similar to our previous study. ${ }^{47}$ We used projector augmented wave (PAW) pseudopotentials ${ }^{62}$ as implemented in the VASP code. $^{63}$ Electronic exchange and correlation were described by the Perdew-Burke-Ernzerhof $(\mathrm{PBE})^{64}$ functional with a $500 \mathrm{eV}$ cutoff energy. A k-mesh of $9 \times 9 \times 1 \mathrm{k}$-points and $5 \times 5$ $\times 1$ k-points were used for a black phosphorus unit cell and $2 \times$ 3 supercell, respectively. Through self-consistent iterations, a total convergence of better than $1 \mathrm{meV} /$ atom was achieved. For each phosphorus oxide species simulated, we first relaxed the structure and optimized the geometry. Additionally, we performed Bader population analysis, ${ }^{65}$ calculating the net 

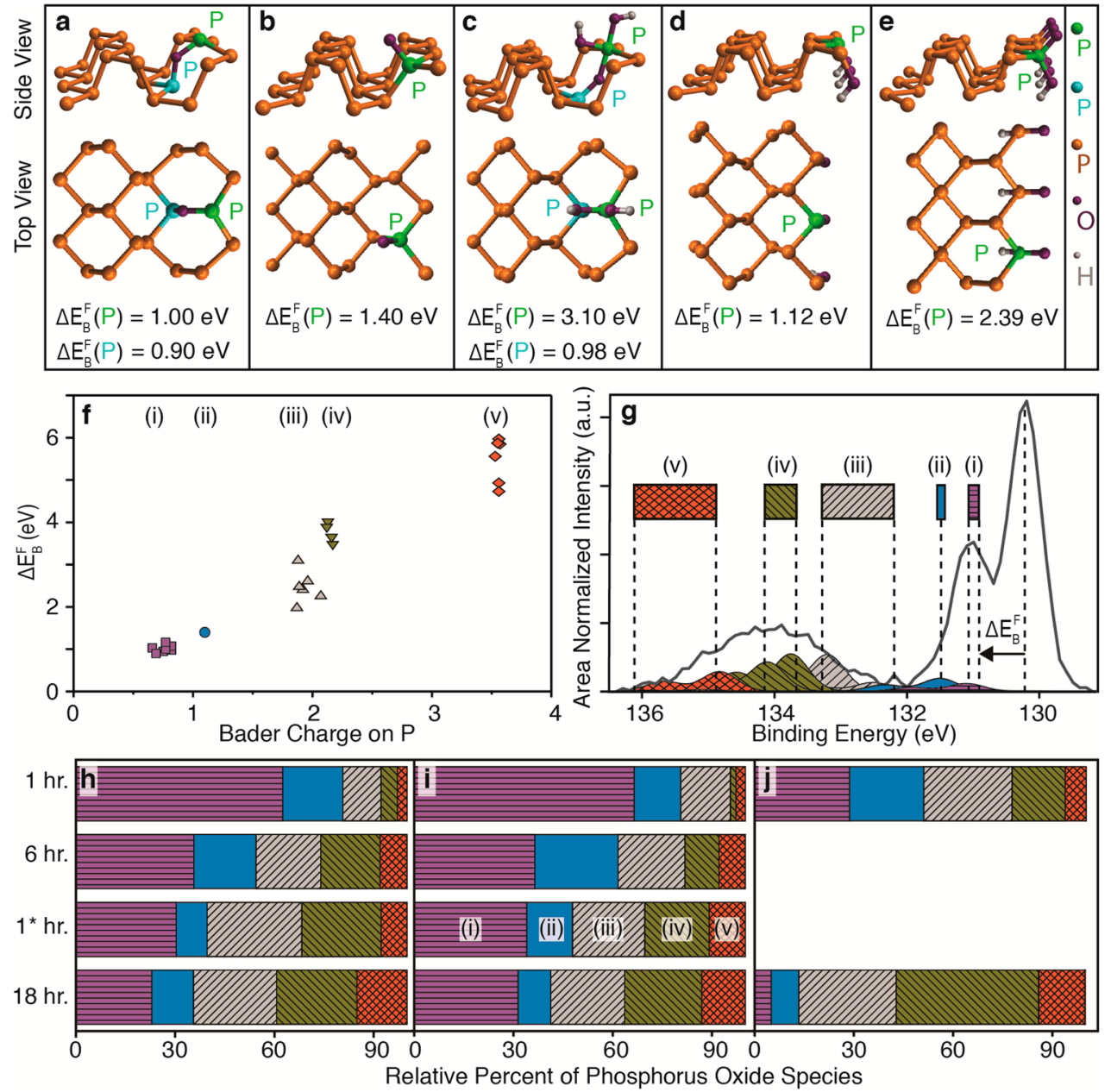

Figure 5. Deconvolution of XPS spectra of oxidized phosphorene. (a-e) Ball and stick figures of oxidized black phosphorus structures are shown from the side and top views. $(a-c)$ Surface phosphorus oxides from groups $\mathrm{i}-\mathrm{iii}$ are shown. ( $\mathrm{d}$ and $\mathrm{e}$ ) Edge oxidized species from group $\mathrm{i}$ and iii are displayed. $\Delta E_{\mathrm{B}}{ }^{\mathrm{F}}$ is shown below each species. (f) Correlation between $\Delta E_{\mathrm{B}}{ }^{\mathrm{F}}$ and Bader charge for the 24 calculated structures. The oxide species are easily divided into five groups. ( $g$ ) Using our five groups, we deconvolute the spectrum of phosphorene exposed to $\mathrm{H}_{2} \mathrm{O} / \mathrm{O}_{2}$ for $18 \mathrm{~h}$. The deconvoluted doublets have the same fwhm as the parent unoxidized material. $(\mathrm{h}-\mathrm{j})$ Percentages of the five classes of oxide species produced from (h) $\mathrm{O}_{2}$, (i) $\mathrm{H}_{2} \mathrm{O} / \mathrm{N}_{2}$, and (j) $\mathrm{H}_{2} \mathrm{O} / \mathrm{O}_{2}$ after 1,6 , and18 h. The series-exposed samples are also shown, indicated by the $1^{*}$ hr. As noted in panel i, group $\mathrm{i}$ is purple, group ii is blue, group iii is gray, group iv is green, and group $\mathrm{v}$ is orange. The $6 \mathrm{~h}$ exposures for $\mathrm{H}_{2} \mathrm{O} / \mathrm{O}_{2}$ oxidants were contaminated and are therefore not shown.

charge of the oxidized phosphorus atom. Unoxidized and related oxidized phosphorene monolayers were represented using the same approach as in the previous study, which surveyed $2 \mathrm{D}$ black phosphorus oxides of the basal surface and oxidic fragments with oxidation states of $+2,+3$, and $+5 .{ }^{47}$ Here, we extend the previous DFT survey to comprehensively include lower oxidation states $(+1,+2)$ as well as oxides that can form at the edges and steps of $2 \mathrm{D}$ flakes, such as those shown in Figures 5a-e. In DFT calculations, edge structures that have been passivated by hydroxyl or peroxy acid groups have been represented by a periodic array of ribbons separated by a vacuum region of $\gtrsim 15 \AA$.

We observed a correlation between Bader charge and $\Delta E_{\mathrm{B}}{ }^{\mathrm{F}}$ of oxidized phosphorus atoms, as shown in Figure 5f. As the Bader charge of the phosphorus atom increased, the core electron binding energy shift increased, in agreement with previous work. ${ }^{47}$ This correlation allowed for the division of oxide species into 5 groups, depicted in Figures $5 \mathrm{f}$ and g, based on oxidation state and $\Delta E_{\mathrm{B}}{ }^{\mathrm{F}}$ : (i) +1 with 3 bonds, 0.90-1.16 $\mathrm{eV}$ (Figures 5a, c, d), (ii) +2 with 5 bonds, $1.40 \mathrm{eV}$ (Figure 5b), (iii) +3 with 5 bonds, $1.98-3.10 \mathrm{eV}$ (Figures $5 \mathrm{c}$ and e), (iv) +3 with 3 bonds, $3.48-4.01 \mathrm{eV}$, and $(\mathrm{v})+5$ with 5 bonds, $4.73-$ $5.97 \mathrm{eV}$. Within the same group, we found that edge oxides have binding energy shifts similar to those of basal surface oxides. For example, the basal oxide shown in Figure 5a has a binding energy shift similar to that of the edge oxide shown in Figure 5d. Thus, XPS cannot distinguish between edge and basal surface oxides.

3.4. Deconvolution of XPS Spectra. Using the calculated $\Delta E_{\mathrm{B}}^{\mathrm{F}}$ for each oxide, we deconvoluted the experimental spectra from Figure 2 using the same method employed in previous literature. ${ }^{47}$ To do this, we fit the unoxidized $2 \mathrm{D}$ black phosphorus $2 \mathrm{p}$ peaks at 130.1 and $131.0 \mathrm{eV}$ and identified the fwhm. We iteratively fit peaks for each oxide group until the cumulative fit converged with a chi-squared tolerance of $10^{-12}$. The deconvolution of the $18 \mathrm{~h} \mathrm{H}_{2} \mathrm{O} / \mathrm{O}_{2}$ exposure is shown as an example in Figure $5 \mathrm{~g}$. In all of our spectra, we did not observe a binding energy shift corresponding to group $\mathrm{v}$ small molecules such as $\mathrm{H}_{3} \mathrm{PO}_{4}$. These molecules have a larger binding energy shift than other group $\mathrm{v}$ oxides. We suspect that these small molecules were produced but, most likely, these 


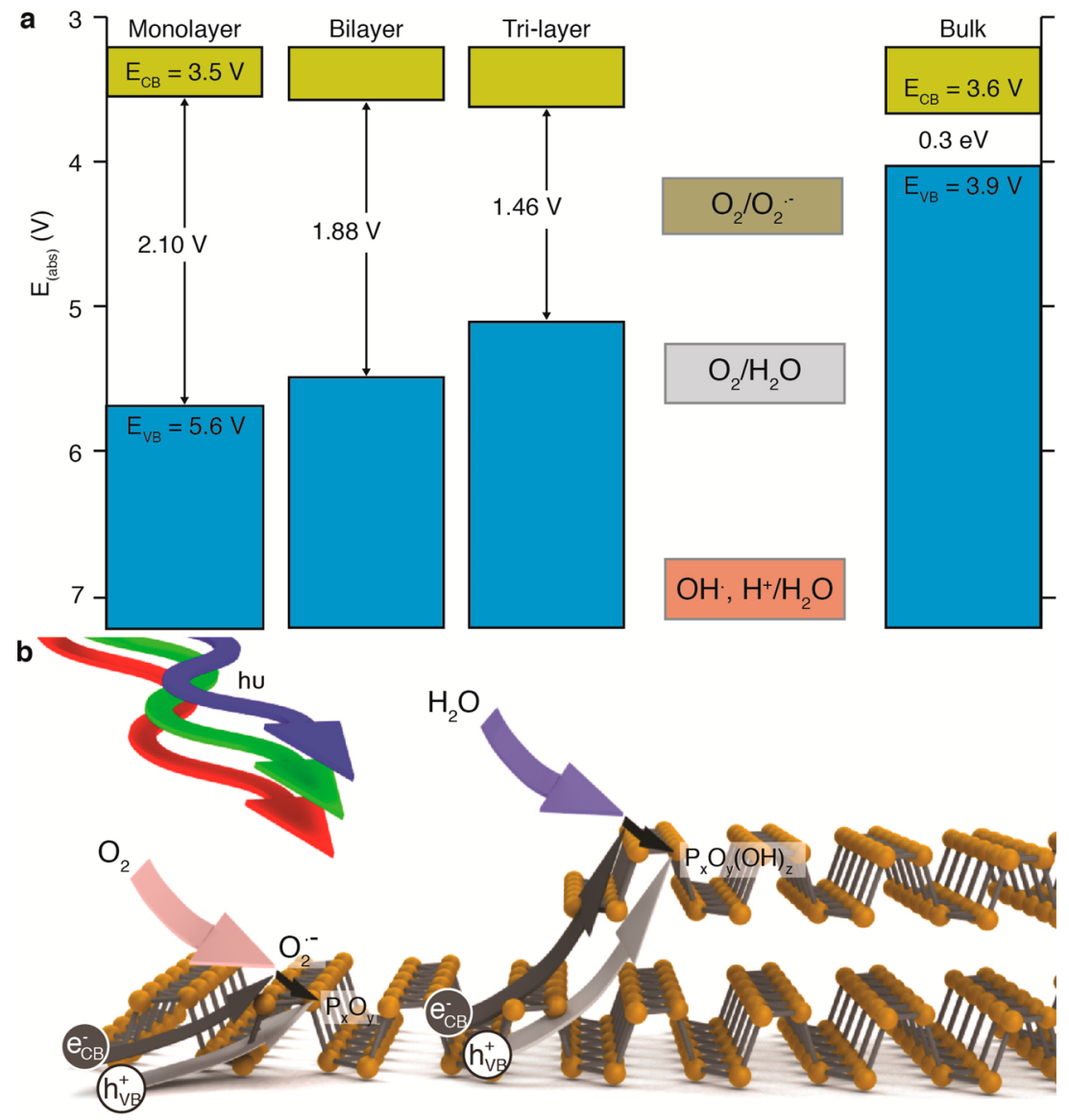

Figure 6. Oxidation mechanism of $2 \mathrm{D}$ black phosphorus flakes. (a) The band diagram for thicknesses of 1-, 2-, and 3-layer and bulk black phosphorus is depicted. The absolute reduction potentials for $\mathrm{O}_{2} / \mathrm{O}_{2}{ }^{-}$and $\mathrm{OH}, \mathrm{H}^{+} / \mathrm{H}_{2} \mathrm{O}$ at $25{ }^{\circ} \mathrm{C}$ for acidic to neutral $\mathrm{pH}$ values (Table 2) are shown. (b) A graphical depiction of the oxidation of $2 \mathrm{D}$ black phosphorus by $\mathrm{O}_{2}$ or $\mathrm{H}_{2} \mathrm{O}$. Photoexcitation of the material produces an electron-hole pair; the electron $e^{-}$CB and hole $h^{+}$VB preferentially move to the thicker region of the $2 \mathrm{D}$ material. Oxidation by $\mathrm{H}_{2} \mathrm{O}$ occurs at defect sites, preferentially on thicker regions of a flake. Oxidation by $\mathrm{O}_{2}$ occurs on the basal surface of $2 \mathrm{D}$ black phosphorus via a one-electron transfer to $\mathrm{O}_{2}$.

small molecules were removed in the high vacuum conditions $\left(10^{-9}\right.$ Torr $)$ of the XPS instrument.

We calculated the relative abundance of each group of oxide species. Histograms depicting the percent of each oxide group after exposure to oxidants $\mathrm{O}_{2}, \mathrm{H}_{2} \mathrm{O} / \mathrm{N}_{2}$, or $\mathrm{H}_{2} \mathrm{O} / \mathrm{O}_{2}$ are depicted in Figures $5 \mathrm{~h}-\mathrm{j}$, respectively. As exposure time increased, the relative amount of species with low oxidation states decreased, while higher oxidation states increased. Moreover, the series-exposed samples such as the sample oxidized by $\mathrm{H}_{2} \mathrm{O} / \mathrm{N}_{2}$ for $5 \mathrm{~min}$ and then $\mathrm{O}_{2}$ for $1 \mathrm{~h}$ represented by the $1^{*} \mathrm{hr}$ in Figure $5 \mathrm{~h}$ show more highly oxidized species than exposure to a single-oxidant such as oxidation by $\mathrm{O}_{2}$ for 6 $\mathrm{h}$ in Figure $5 \mathrm{~h}$. These findings are consistent with an oxidation that is catalyzed by the presence of reaction byproducts.

3.5. Mechanism of Oxidation by $\mathrm{O}_{2}$ or $\mathrm{H}_{2} \mathrm{O}$. To understand the mechanisms of basal surface oxidation by $\mathrm{O}_{2}$ and defect-mediated oxidation by $\mathrm{H}_{2} \mathrm{O}$, we compared the band structure of 2D black phosphorus (Figure 6a) ${ }^{10,26,66,67}$ and the reduction potentials of likely redox couples (Table 2, Figure $6 a) \cdot{ }^{68-75}$ As shown in Figure 6a, the band gap of the $2 \mathrm{D}$ black

Table 2. Absolute Reduction Potentials $E_{a b s}$ at $25^{\circ} \mathrm{C}$

$\begin{array}{ccc}\text { couple } & \mathrm{pH} & \mathrm{pH} \mathrm{0} \\ \mathrm{O}_{2}+\mathrm{e}^{-} \rightarrow \mathrm{O}_{2}^{-70-73} & -4.51 \pm 0.02 \mathrm{~V} & -4.09 \pm 0.02 \mathrm{~V} \\ \mathrm{OH}+\mathrm{H}^{+}+\mathrm{e}^{-} \rightarrow \mathrm{H}_{2} \mathrm{O}^{74,75} & -6.75 \pm 0.02 \mathrm{~V} & -7.16 \pm 0.02 \mathrm{~V}\end{array}$

phosphorus decreases with increasing thickness. ${ }^{26,66,67} \mathrm{We}$ consider only one-electron transfer from the conduction band and one-hole transfer from the valence band because the illumination intensities in our experiments produce fewer than one photoexcited electron/hole per phosphorene flake at steady state on average. Prior work suggested that a photoexcited electron can be transferred from the conduction band of black phosphorus to $\mathrm{O}_{2}$, producing the superoxide radical $\mathrm{O}_{2}{ }^{--}$, as demonstrated in eq $1 .^{37}$

$$
\mathrm{O}_{2}+\mathrm{e}_{\mathrm{CB}}^{-} \rightarrow \mathrm{O}_{2}^{-}
$$

On the basis of the reduction potential for forming superoxide (Figure 6a, Table 2 for neutral and acidic $\mathrm{pHs}$ ), the proposed one-electron transfer from the conduction band of black phosphorus to oxygen is plausible. The superoxide then reacts with oxidized phosphorene, producing a phosphorus oxide (Figure 6b). This model is consistent with XPS observations (Figure 2a) which showed the formation of phosphorus oxides across the basal surface of phosphorene, as inferred from TEM images (Figures $3 a-d$ ).

To understand how $\mathrm{H}_{2} \mathrm{O}$ oxidizes $2 \mathrm{D}$ black phosphorus, we considered the possibility of a photoexcited hole transfer from the $2 \mathrm{D}$ material to $\mathrm{H}_{2} \mathrm{O}$, such as that in eq 2 .

$$
\mathrm{H}_{2} \mathrm{O}+\mathrm{h}_{\mathrm{VB}}^{+} \rightarrow \mathrm{OH}^{-}+\mathrm{H}^{+}
$$


On the basis of the reduction potential for forming a radical hydroxide and proton relative to the valence band of bulk and 2D black phosphorus (Table 2, Figure 6a), it is not thermodynamically favorable for this reaction to occur. Likewise, there is no thermodynamically favorable one-electron transfer from the conduction band to $\mathrm{H}_{2} \mathrm{O}$. We conclude that the first step in the reaction of $2 \mathrm{D}$ black phosphorus with $\mathrm{H}_{2} \mathrm{O}$ is not an electron or hole transfer.

An important observation about the mechanism of waterphosphorene reactions is that the reactions occur at steps, edges, and grain boundaries (Figures $3 \mathrm{e}$ and g). At these defect sites, atoms are likely to have relatively unstable bonding configurations such as a phosphorus atom with an oxidation state of +2 (Figure $5 b$ ). Therefore, at these defect sites, a direct chemical reaction with $\mathrm{H}_{2} \mathrm{O}$ must be thermodynamically favored. The observation that pitting occurs at a step (Figure $3 \mathrm{e}$ ) or edge (Figure $3 \mathrm{~g}$ ) is consistent with the need for a defect state to initiate oxidation. Furthermore, due to the relative positions of the reduced band gap with increasing thickness, photoexcited electron-hole pairs preferentially move to thicker regions of the flake. Therefore, it can be inferred that oxidation occurs at a higher rate on the thicker side of the flake. The observed pitting of thicker regions at defect sites of steps is consistent with this proposed mechanism and supports firstprinciples calculations that $\mathrm{H}_{2} \mathrm{O}$ cannot lead to the oxidation of pristine, defect-free material on the basal surface. ${ }^{50}$ Our experimental observations suggest that the reaction with $\mathrm{H}_{2} \mathrm{O}$ at a defect site does not result in a self-passivating barrier to further reaction; the continued etching of phosphorene flakes over time indicates that the oxide that forms at defects is relatively unstable. Additionally, it is important to highlight that oxidation by $\mathrm{H}_{2} \mathrm{O}$ at defect sites supports our observations of accelerated oxidation in samples exposed to both oxygen and water. When the pristine basal surface of the material reacts with $\mathrm{O}_{2}$, numerous defect sites are created. The increased concentration of defect sites leads to a faster reaction with water. This experimental observation validates first-principle studies of the susceptibility of the basal oxide to further hydrolysis. ${ }^{50}$

These insights provide a pathway to oxidize the basal surface with $\mathrm{O}_{2}$ or the defect sites with $\mathrm{H}_{2} \mathrm{O}$. This may lead to improved control over the properties of phosphorene as well as new routes to stabilize the material against oxidation. We emphasize that these insights were made possible only through the use of high purity $\mathrm{O}_{2}$ and $\mathrm{H}_{2} \mathrm{O}$.

\section{CONCLUSION}

In this work, we studied the oxidation of thin films and individual flakes of $2 \mathrm{D}$ black phosphorus exposed to high-purity $\mathrm{O}_{2}, \mathrm{H}_{2} \mathrm{O}$, and their mixtures. We found that both $\mathrm{H}_{2} \mathrm{O}$ and $\mathrm{O}_{2}$ can oxidize the $2 \mathrm{D}$ material. For high-purity, dry $\mathrm{O}_{2}$ environments, XPS showed that the material oxidizes, but we did not observe any changes in the shape or integrity of $2 \mathrm{D}$ flakes in TEM images. We observed primarily the presence of low oxidation state species $(+1,+2)$ in short-term exposures to $\mathrm{O}_{2}$. By investigating the band structure of black phosphorus and the reduction potentials of $\mathrm{O}_{2} / \mathrm{O}_{2}$, we easily saw that black phosphorus can be oxidized by $\mathrm{O}_{2}$. This supports a model in which high-purity $\mathrm{O}_{2}$ environments lead to oxidation of the van der Waals surface of 2D black phosphorus.

In contrast, oxidation of $2 \mathrm{D}$ black phosphorus by $\mathrm{H}_{2} \mathrm{O}$ physically degraded the material. Initially, the material exhibited pitting at steps on the thicker side of the flake, which then migrated farther into the thicker region of the flake as exposure to $\mathrm{H}_{2} \mathrm{O}$ continued, ultimately resulting in surface pitting. Additionally, edges of the material were corroded during oxidation by $\mathrm{H}_{2} \mathrm{O}$. With continued oxidation, these degradation processes resulted in the loss of layers. The band structure of black phosphorus and the reduction potential of $\mathrm{OH}, \mathrm{H}^{+} / \mathrm{H}_{2} \mathrm{O}$ provides more insight into the mechanism of oxidation. It is thermodynamically unfavorable for black phosphorus to be oxidized by $\mathrm{H}_{2} \mathrm{O}$. With evidence of oxidation in XPS and TEM, this supports a model in which $\mathrm{H}_{2} \mathrm{O}$ reacts preferentially with defect sites such as those at steps and edges.

Finally, we found that 2D black phosphorus degrades most rapidly in the environments containing both $\mathrm{H}_{2} \mathrm{O}$ and $\mathrm{O}_{2}$, exhibiting a greater abundance of phosphorus in higher oxidation states $(+3,+5)$. From our series-exposed samples, we determined that residual quantities of oxide byproducts accelerate or catalyze the oxidation of the material. Furthermore, the physical degradation of the material after exposure to ambient conditions was the same as that in $\mathrm{H}_{2} \mathrm{O}$ only environments. We conclude that $\mathrm{H}_{2} \mathrm{O}$ or reaction byproducts from $\mathrm{H}_{2} \mathrm{O}$ oxidation catalyze oxidation by $\mathrm{O}_{2}$.

The use of high purity $\mathrm{O}_{2}$ or $\mathrm{H}_{2} \mathrm{O}$ provides control of the phosphorus oxide composition and site selectivity for oxide formation. This knowledge is a step forward in surface reaction chemistries of $2 \mathrm{D}$ black phosphorus. Controlled oxidation of 2D black phosphorus opens pathways to selectively oxidize basal surface and edge sites of the material, opening pathways for site-selective surface functionalization. Additionally, this work may provide an avenue to synthesize $2 \mathrm{D}$ phosphorene oxide, but more work is needed to understand if the oxide is self-limited.

\section{ASSOCIATED CONTENT}

\section{Supporting Information}

The Supporting Information is available free of charge on the ACS Publications website at DOI: 10.1021/acsami.6b16111.

General material handling, black phosphorus synthesis, liquid exfoliation, thin film assembly, oxidant exposure, TEM images, and Raman spectroscopy (PDF)

\section{AUTHOR INFORMATION}

\section{Corresponding Author}

* E-mail: sw@unc.edu.

ORCID

Huaihong Guo: 0000-0001-7094-2878

David Tománek: 0000-0003-1131-4788

Scott C. Warren: 0000-0002-2883-0204

Notes

The authors declare no competing financial interest.

\section{ACKNOWLEDGMENTS}

S.C.W. acknowledges support of this research by UNC Chapel Hill startup funds and the ACS Petroleum Research Fund grant 55497-DNI3. T.Y. acknowledges the NSFC under Grants 51331006 and U1537204 for financial support. D.T. acknowledges support by the NSF/AFOSR EFRI 2-DARE Grant EFMA-1433459. H.G. acknowledges the support by the Liaoning Province Doctor Startup Fund (Grant 201601325) and Liaoning Shihua University Grant 2016XJJ-044. This work was performed in part at the Chapel Hill Analytical and Nanofabrication Laboratory, CHANL, a member of the North 
Carolina Research Triangle Nanotechnology Network, RTNN, which is supported by the National Science Foundation, Grant ECCS-1542015, as part of the National Nanotechnology Coordinated Infrastructure, NNCI. Raman spectroscopy measurements were performed using a Renishaw inVia Raman microscope in the UNC EFRC Instrumentation Facility established by the UNC EFRC Center for Solar Fuels, an Energy Frontier Research Center funded by the U.S. Department of Energy, Office of Science, Office of Basic Energy Sciences under Award DE-SC0001011. We acknowledge C. Donley for assistance with XPS and UPS measurements, W. Ambrose for assistance with TEM images, B. Geil for preparation of $\mathrm{Au} / \mathrm{Si}$ wafers, and T. W. Farnsworth for helpful discussions.

\section{REFERENCES}

(1) Bolotin, K. I.; Sikes, K. J.; Jiang, Z.; Klima, M.; Fudenberg, G.; Hone, J.; Kim, P.; Stormer, H. L. Ultrahigh Electron Mobility in Suspended Graphene. Solid State Commun. 2008, 146, 351-355.

(2) Zhu, Y.; Murali, S.; Cai, W.; Li, X.; Suk, J. W.; Potts, J. R.; Ruoff, R. S. Graphene and Graphene Oxide: Synthesis, Properties, and Applications. Adv. Mater. 2010, 22, 3906-3924.

(3) Dreyer, D. R.; Park, S.; Bielawski, C. W.; Ruoff, R. S. The Chemistry of Graphene Oxide. Chem. Soc. Rev. 2010, 39, 228-240.

(4) Loh, K. P.; Bao, Q.; Eda, G.; Chhowalla, M. Graphene Oxide as a Chemically Tunable Platform for Optical Applications. Nat. Chem. 2010, 2, 1015-1024.

(5) Chen, D.; Feng, H.; Li, J. Graphene Oxide: Preparation, Functionalization, and Electrochemical Applications. Chem. Rev. 2012, 112, 6027-6053.

(6) Edmonds, M. T.; Tadich, A.; Carvalho, A.; Ziletti, A.; O’Donnell, K. M.; Koenig, S. P.; Coker, D. F.; Özyilmaz, B.; Castro Neto, A. H.; Fuhrer, M. S. Creating a Stable Oxide at the Surface of Black Phosphorus. ACS Appl. Mater. Interfaces 2015, 7, 14557-14562.

(7) Island, J. O.; Steele, G. A.; van der Zant, H. S. J.; CastellanosGomez, A. Environmental Instability of Few-Layer Black Phosphorus. 2D Mater. 2015, 2, 11002.

(8) Ryder, C. R.; Wood, J. D.; Wells, S. A.; Yang, Y.; Jariwala, D.; Marks, T. J.; Schatz, G. C.; Hersam, M. C. Covalent Functionalization and Passivation of Exfoliated Black Phosphorus via Aryl Diazonium Chemistry. Nat. Chem. 2016, 8, 597-602.

(9) Hu, W.; Lin, L.; Yang, C.; Dai, J.; Yang, J. Edge-Modified Phosphorene Nanoflake Heterojunctions as Highly Efficient Solar Cells. Nano Lett. 2016, 16, 1675-1682.

(10) Woomer, A. H.; Farnsworth, T. W.; Hu, J.; Wells, R. A.; Donley, C. L.; Warren, S. C. Phosphorene: Synthesis, Scale-Up, and Quantitative Optical Spectroscopy. ACS Nano 2015, 9, 8869-8884.

(11) Zhang, S.; Yang, J.; Xu, R.; Wang, F.; Li, W.; Ghufran, M.; Zhang, Y.-W.; Yu, Z.; Zhang, G.; Qin, Q.; Lu, Y. Extraordinary Photoluminescence and Strong Temperature/ Angle-Dependent Raman Responses in Few-Layer Phosphorene. ACS Nano 2014, 8, 9590-9596.

(12) Liang, L.; Wang, J.; Lin, W.; Sumpter, B. G.; Meunier, V.; Pan, M. Electronic Bandgap and Edge Reconstruction in Phosphorene Materials. Nano Lett. 2014, 14, 6400-6406.

(13) Akahama, Y.; Endo, S.; Narita, S. Electrical Properties of Black Phosphorus Single Crystals. J. Phys. Soc. Jpn. 1983, 52, 2148-2155.

(14) Takao, Y.; Asahina, H.; Morita, A. Electronic Structure of Black Phosphorus in Tight Binding Approach. J. Phys. Soc. Jpn. 1981, 50, $3362-3369$.

(15) Tran, V.; Soklaski, R.; Liang, Y.; Yang, L. Layer-Controlled Band Gap and Anisotropic Excitons in Few-Layer Black Phosphorus. Phys. Rev. B: Condens. Matter Mater. Phys. 2014, 89, 235319.

(16) Xia, F.; Wang, H.; Jia, Y. Rediscovering Black Phosphorus as an Anisotropic Layered Material for Optoelectronics and Electronics. Nat. Commun. 2014, 5, 5458.
(17) Wang, X.; Jones, A. M.; Seyler, K. L.; Tran, V.; Jia, Y.; Zhao, H.; Wang, H.; Yang, L.; Xu, X.; Xia, F. Highly Anisotropic and Robust Excitons in Monolayer Black Phosphorus. Nat. Nanotechnol. 2015, 10, 517-521.

(18) Yuan, H.; Liu, X.; Afshinmanesh, F.; Li, W.; Xu, G.; Sun, J.; Lian, B.; Curto, A. G.; Ye, G.; Hikita, Y.; Shen, Z.; Zhang, S.-C.; Chen, X.; Brongersma, M.; Hwang, H. Y.; Cui, Y. Polarization-Sensitive Broadband Photodetector Using a Black Phosphorus Vertical $\mathrm{P}-\mathrm{n}$ Junction. Nat. Nanotechnol. 2015, 10, 707-713.

(19) Buscema, M.; Groenendijk, D. J.; Blanter, S. I.; Steele, G. A.; van der Zant, H. S. J.; Castellanos-Gomez, A. Fast and Broadband Photoresponse of Few-Layer Black Phosphorus Field-Effect Transistors. Nano Lett. 2014, 14, 3347-3352.

(20) Li, L.; Yu, Y.; Ye, G. J.; Ge, Q.; Ou, X.; Wu, H.; Feng, D.; Chen, X. H.; Zhang, Y. Black Phosphorus Field-Effect Transistors. Nat. Nanotechnol. 2014, 9, 372-377.

(21) Liu, H.; Neal, A. T.; Zhu, Z.; Luo, Z.; Xu, X.; Tománek, D.; Ye, P. D. Phosphorene: An Unenexplored 2D Semiconductor with a High Hole Mobility. ACS Nano 2014, 8, 4033-4041.

(22) Buscema, M.; Groenendijk, D. J.; Steele, G. A.; van der Zant, H. S. J.; Castellanos-Gomez, A. Photovoltaic Effect in Few-Layer Black Phosphorus PN Junctions Defined by Local Electrostatic Gating. Nat. Commun. 2014, 5, 4651.

(23) Koenig, S. P.; Doganov, R. A.; Schmidt, H.; Castro Neto, A. H.; Özyilmaz, B. Electric Field Effect in Ultrathin Black Phosphorus. Appl. Phys. Lett. 2014, 104, 103106.

(24) Dai, J.; Zeng, X. C. Bilayer Phosphorene: Effect of Stacking Order on Bandgap and Its Potential Applications in Thin-Film Solar Cells. J. Phys. Chem. Lett. 2014, 5, 1289-1293.

(25) Deng, Y.; Luo, Z.; Conrad, N. J.; Liu, H.; Gong, Y.; Najmaei, S.; Ajayan, P. M.; Lou, J.; Xu, X.; Ye, P. D. Black Phosphorus-monolayer MoS2 van Der Waals Heterojunction P-n Diode. ACS Nano 2014, 8, 8292-8299.

(26) Hu, J.; Guo, Z.; Mcwilliams, P. E.; Darges, J. E.; Druffel, D. L.; Moran, A. M.; Warren, S. C. Band Gap Engineering in a 2D Material for Solar-to-Chemical Energy Conversion. Nano Lett. 2016, 16, 7479.

(27) Baba, M.; Takeda, Y.; Shibata, K.; Ikeda, T.; Morita, A. Optical Properties of Black Phosphorus and Its Application to the Infrared Detector. Jpn. J. Appl. Phys. 1989, 28, L2104-L2106.

(28) Engel, M.; Steiner, M.; Avouris, P. Black Phosphorus Photodetector for Multispectral, High-Resolution Imaging. Nano Lett. 2014, 14, 6414-6417.

(29) Park, C.-M.; Sohn, H.-J. Black Phosphorus and Its Composite for Lithium Rechargeable Batteries. Adv. Mater. 2007, 19, 2465-2468.

(30) Sun, J.; Zheng, G.; Lee, H.-W.; Liu, N.; Wang, H.; Yao, H.; Yang, W.; Cui, Y. Formation of Stable Phosphorus-Carbon Bond for Enhanced Performance in Black Phosphorus Nanoparticle-Graphite Composite Battery Anodes. Nano Lett. 2014, 14, 4573-4580.

(31) Abbas, A. N.; Liu, B.; Chen, L.; Ma, Y.; Cong, S.; Aroonyadet, N.; Köpf, M.; Nilges, T.; Zhou, C. Black Phosphorus Gas Sensors. ACS Nano 2015, 9, 5618-5624.

(32) Yasaei, P.; Behranginia, A.; Foroozan, T.; Asadi, M.; Kim, K.; Khalili-Araghi, F.; Salehi-Khojin, A. Stable and Selective Humidity Sensing Using Stacked Black Phosphorus Flakes. ACS Nano 2015, 9, 9898-9905.

(33) Lu, J.; Wu, J.; Carvalho, A.; Ziletti, A.; Liu, H.; Tan, J.; Chen, Y.; Castro Neto, A. H.; Özyilmaz, B.; Sow, C. H. Bandgap Engineering of Phosphorene by Laser Oxidation toward Functional 2D Materials. ACS Nano 2015, 9, 10411-10421.

(34) Yao, Y.; Zhang, H.; Sun, J.; Ma, W.; Li, L.; Li, W.; Du, J. Novel QCM Humidity Sensors Using Stacked Black Phosphorus Nanosheets as Sensing Film. Sens. Actuators, B 2017, 244, 259-264.

(35) Wang, H.; Yang, X.; Shao, W.; Chen, S.; Xie, J.; Zhang, X.; Wang, J.; Xie, Y. Ultrathin Black Phosphorus Nanosheets for Efficient Singlet Oxygen Generation. J. Am. Chem. Soc. 2015, 137, 1137611382.

(36) Sun, Z.; Xie, H.; Tang, S.; Yu, X.-F.; Guo, Z.; Shao, J.; Zhang, H.; Huang, H.; Wang, H.; Chu, P. K. Ultrasmall Black Phosphorus 
Quantum Dots: Synthesis and Use as Photothermal Agents. Angew. Chem., Int. Ed. 2015, 54, 11526-11530.

(37) Favron, A.; Gaufrès, E.; Fossard, F.; Phaneuf-L'Heureux, A.-L.; Tang, N. Y.-W.; Lévesque, P. L.; Loiseau, A.; Leonelli, R.; Francoeur, S.; Martel, R. Photooxidation and Quantum Confinement Effects in Exfoliated Black Phosphorus. Nat. Mater. 2015, 14, 826-832.

(38) Wood, J. D.; Wells, S. A.; Jariwala, D.; Chen, K.-S.; Cho, E.; Sangwan, V. K.; Liu, X.; Lauhon, L. J.; Marks, T. J.; Hersam, M. C. Effective Passivation of Exfoliated Black Phosphorus Transistors against Ambient Degradation. Nano Lett. 2014, 14, 6964-6970.

(39) Ziletti, A.; Carvalho, A.; Trevisanutto, P. E.; Campbell, D. K.; Coker, D. F.; Castro Neto, A. H. Phosphorene Oxides: Bandgap Engineering of Phosphorene by Oxidation. Phys. Rev. B: Condens. Matter Mater. Phys. 2015, 91, 85407.

(40) Gamage, S.; Li, Z.; Yakovlev, V. S.; Lewis, C.; Wang, H.; Cronin, S. B.; Abate, Y. Nanoscopy of Black Phosphorus Degradation. Adv. Mater. Interfaces 2016, 3, 1600121.

(41) Huang, Y.; Qiao, J.; He, K.; Bliznakov, S.; Sutter, E.; Chen, X.; Luo, D.; Meng, F.; Su, D.; Decker, J.; Ji, W.; Ruoff, R. S.; Sutter, P. Interaction of Black Phosphorus with Oxygen and Water. Chem. Mater. 2016, 28, 8330-8339.

(42) Luo, W.; Zemlyanov, D. Y.; Milligan, C. A.; Du, Y.; Yang, L.; Wu, Y.; Ye, P. D. Surface Chemistry of Black Phosphorus under a Controlled Oxidative Environment. Nanotechnology 2016, 27, 434002.

(43) Serrano-Ruiz, M.; Caporali, M.; Ienco, A.; Piazza, V.; Heun, S.; Peruzzini, M. The Role of Water in the Preparation and Stabilization of High-Quality Phosphorene Flakes. Adv. Mater. Interfaces 2016, 3, 1500441.

(44) Gan, Z. X.; Sun, L. L.; Wu, X. L.; Meng, M.; Shen, J. C.; Chu, P. K. Tunable Photoluminescence from Sheet-like Black Phosphorus Crystal by Electrochemical Oxidation. Appl. Phys. Lett. 2015, 107, 21901.

(45) Wang, G. X.; Pandey, R.; Karna, S. P. Phosphorene Oxide: Stability and Electronic Properties of a Novel Two-Dimensional Material. Nanoscale 2015, 7, 524-531.

(46) Yau, S.-L.; Moffat, T. P.; Bard, A. J.; Zhang, Z.; Lerner, M. M. STM of the (010) Surface of Orthorhombic Phosphorus. Chem. Phys. Lett. 1992, 198, 383-388.

(47) Yang, T.; Dong, B.; Wang, J.; Zhang, Z.; Guan, J.; Kuntz, K.; Warren, S. C.; Tomanek, D. Interpreting Core-Level Spectra of Oxidizing Phosphorene: Theory and Experiment. Phys. Rev. B: Condens. Matter Mater. Phys. 2015, 92, 125412.

(48) Pei, J.; Gai, X.; Yang, J.; Wang, X.; Yu, Z.; Choi, D.-Y.; LutherDavies, B.; Lu, Y. Producing Air-Stable Monolayers of Phosphorene and Their Defect Engineering. Nat. Commun. 2016, 7, 10450.

(49) Kwon, H.; Seo, S. W.; Kim, T. G.; Lee, E. S.; Lanh, P. T.; Yang, S.; Ryu, S.; Kim, J. W. Ultrathin and Flat Layer Black Phosphorus Fabricated by Reactive Oxygen and Water Rinse. ACS Nano 2016, 10, 8723-8731.

(50) Wang, G.; Slough, W. J.; Pandey, R.; Karna, S. P. Degradation of Phosphorene in Air: Understanding at Atomic Level. 2D Mater. 2016, 3, 25011 .

(51) Kang, J.; Wells, S. A.; Wood, J. D.; Lee, J.-H.; Liu, X.; Ryder, C. R.; Zhu, J.; Guest, J. R.; Husko, C. A.; Hersam, M. C. Stable Aqueous Dispersions of Optically and Electronically Active Phosphorene. Proc. Natl. Acad. Sci. U. S. A. 2016, 113, 11688-11693.

(52) Köpf, M.; Eckstein, N.; Pfister, D.; Grotz, C.; Krüger, I.; Greiwe, M.; Hansen, T.; Kohlmann, H.; Nilges, T. Access and in Situ Growth of Phosphorene-Precursor Black Phosphorus. J. Cryst. Growth 2014, 405, 6-10.

(53) Li, L.; Yu, Y.; Meng, F.; Tan, Y.; Hamers, R. J.; Jin, S. Facile Solution Synthesis of Alpha-FeF3 3H2O Nanowires and Their Conversion to Alpha-Fe2O3 Nanowires for Photoelectrochemical Application. Nano Lett. 2012, 12, 724-731.

(54) Castellanos-Gomez, A.; Vicarelli, L.; Prada, E.; Island, J. O.; Narasimha-Acharya, K. L.; Blanter, S. I.; Groenendijk, D. J.; Buscema, M.; Steele, G. A.; Alvarez, J. V.; Zandbergen, H. W.; Palacios, J. J.; van der Zant, H. S. J. Isolation and Characterization of Few-Layer Black Phosphorus. 2D Mater. 2014, 1, 25001.
(55) Hayasi, Y.; Takahashi, T.; Asahina, H.; Sagawa, T.; Morita, A.; Shirotani, I. Electronic Structure of Black Phosphorus Studied by Polarized Soft-X-Ray Emission and Absorption Spectroscopy. Phys. Rev. B: Condens. Matter Mater. Phys. 1984, 30, 1891-1895.

(56) Taniguchi, M.; Suga, S.; Seki, M.; Sakamoto, H.; Kanzaki, H.; Akahama, Y.; Terada, S.; Endo, S.; Narita, S. Valence Band and CoreLevel Photoemission Spectra of Black Phosphorus Single Crystals. Solid State Commun. 1983, 45, 59-61.

(57) Moffat, T. P.; Latanision, R. M.; Ruf, R. R. An X-Ray Photoelectron Spectroscopy Study of Chromium-Metalloid Alloys-III. Electrochim. Acta 1995, 40, 1723-1734.

(58) Johansson, B.; Mårtensson, N. Core-Level Binding-Energy Shifts for the Metallic Elements. Phys. Rev. B: Condens. Matter Mater. Phys. 1980, 21, 4427-4457.

(59) Tománek, D.; Kumar, V.; Holloway, S.; Bennemann, K. H. Semiempirical Theory for Surface Core-Level Shifts. Solid State Commun. 1982, 41, 273-279.

(60) Grunze, M.; Brundle, C. R.; Tomanek, D. Adsoprtion and Decomposition of Ammonia on a W(110) Surface: Photoemissison Fingerprinting and Interpretation of the Core Level Binding Energies Using the Equivalen Core Approximation. Surf. Sci. 1982, 119, 133149.

(61) Tománek, D.; Dowben, P. A.; Grunze, M. Thermodynamic Interpretation of Core-Level Binding Energies in Adsorbates. Surf. Sci. 1983, 126, 112-119.

(62) Kresse, G.; Joubert, D. From Ultrasoft Pseudopotentials to the Projector Augmented-Wave Method. Phys. Rev. B: Condens. Matter Mater. Phys. 1999, 59, 1758-1775.

(63) Kresse, G.; Furthmüller, J. Efficient Iterative Schemes for Ab Initio Total-Energy Calculations Using a Plane-Wave Basis Set. Phys. Rev. B: Condens. Matter Mater. Phys. 1996, 54, 11169-11186.

(64) Perdew, J. P.; Burke, K.; Ernzerhof, M. Generalized Gradient Approximation Made Simple. Phys. Rev. Lett. 1996, 77, 3865-3868.

(65) Henkelman, G.; Arnaldsson, A.; Jónsson, H. A Fast and Robust Algorithm for Bader Decomposition of Charge Density. Comput. Mater. Sci. 2006, 36, 354-360.

(66) Cai, Y.; Zhang, G.; Zhang, Y.-W. Layer-Dependent Band Alignment and Work Function of Few-Layer Phosphorene. Sci. Rep. 2014, 4, 6677.

(67) Wang, V.; Kawazoe, Y.; Geng, W. T. Native Point Defects in Few-Layer Phosphorene. Phys. Rev. B: Condens. Matter Mater. Phys. 2015, 91, 45433.

(68) Koppenol, W. H.; Stanbury, D. M.; Bounds, P. L. Electrode Potentials of Partially Reduced Oxygen Species, from Dioxygen to Water. Free Radical Biol. Med. 2010, 49, 317-322.

(69) Pourbaix, M. Atlas of Electrochemical Equilibria in Aqueous Solutions, version 2; National Association of Corrosion Engineers: Houston, TX, 1974; pp 504-511.

(70) Rao, P. S.; Hayon, E. Experimental Determination of the Redox Potential of the Superoxide Radical. $\mathrm{O}_{2}^{-}$. Biochem. Biophys. Res. Commun. 1973, 51, 468-473.

(71) Wood, P. M. The Redox Potential of the System OxygenSuperoxide. FEBS Lett. 1974, 44, 22-24.

(72) Ilan, Y. A.; Czapski, G.; Meisel, D. The One-Electron Transfer Redox Potentials of Free Radicals I. The Oxygen/superoxide System. Biochim. Biophys. Acta, Bioenerg. 1976, 430, 209-224.

(73) Sawyer, D. T.; Valentine, J. S. How Super Is Superoxide? Acc. Chem. Res. 1981, 14, 393-400.

(74) Koppenol, W. H.; Butler, J. Energetics of Interconversion Reactions of Oxyradicals. Adv. Free Radical Biol. Med. 1985, 1, 91-131.

(75) Buettner, G. R. The Pecking Order of Free Radicals and Antioxidants: Lipid Peroxidation, $\alpha$-Tocopherol, and Ascorbate. Arch. Biochem. Biophys. 1993, 300, 535-543. 